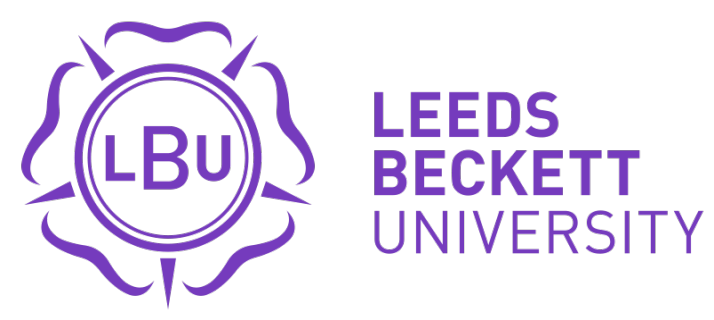

Citation:

Hendricks, S and van Niekerk, T and Sin, DW and Lambert, $M$ and den Hollander, S and Brown, JC and Maree, W and Treu, P and Till, K and Jones, B (2017) Technical determinants of tackle and ruck performance in International rugby union. Journal of Sports Sciences, 36 (5). pp. 522-528. ISSN 1466-447X DOI: https://doi.org/10.1080/02640414.2017.1322216

Link to Leeds Beckett Repository record:

https://eprints.leedsbeckett.ac.uk/id/eprint/3809/

Document Version:

Article (Accepted Version)

The aim of the Leeds Beckett Repository is to provide open access to our research, as required by funder policies and permitted by publishers and copyright law.

The Leeds Beckett repository holds a wide range of publications, each of which has been checked for copyright and the relevant embargo period has been applied by the Research Services team.

We operate on a standard take-down policy. If you are the author or publisher of an output and you would like it removed from the repository, please contact us and we will investigate on a case-by-case basis.

Each thesis in the repository has been cleared where necessary by the author for third party copyright. If you would like a thesis to be removed from the repository or believe there is an issue with copyright, please contact us on openaccess@leedsbeckett.ac.uk and we will investigate on a case-by-case basis. 


\section{Technical determinants of tackle and ruck performance in International Rugby Union}

Sharief Hendricks ${ }^{1,2}$, Tiffany van Niekerk ${ }^{2}$, Drew Wade $\operatorname{Sin}^{2}$, Mike Lambert ${ }^{2,3}$, Steve den

Hollander $^{2}$, James Brown ${ }^{2,3}$, Willie Maree ${ }^{4}$, Paul Treu ${ }^{5}$, Kevin Till ${ }^{1,7}$, Ben Jones ${ }^{1,7,8}$

${ }^{1}$ Leeds Beckett University, Institute for Sport, Physical Activity and Health, Leeds,

United Kingdom

${ }^{2}$ University of Cape Town, Division of Exercise Science and Sports Medicine, Cape

Town, South Africa

${ }^{3}$ VU University, Department of Public \& Occupational Health and the EMGO Institute

Health and Care Research, Amsterdam, The Netherlands

${ }^{4}$ South African Rugby Union, Cape Town, South Africa

${ }^{5}$ Western Province Rugby Union/Stormers

${ }^{7}$ Yorkshire Carnegie Rugby Union Football Club, Leeds, United Kingdom

${ }^{8}$ The Rugby Football League, Leeds, United Kingdom

Correspondence to:

Sharief Hendricks, PhD

Institute for Sport, Physical Activity and Leisure, Centre for Sport Performance, School of Sport, Fairfax Hall,

Headingley Campus, Leeds Beckett University,

Leeds, United Kingdom.

LS6 3QS

sharief.hendricks01@gmail.com

Twitter: @Sharief_H 


\section{Abstract}

The most frequently occurring contact events in rugby union are the tackle and ruck. The ability repeatedly to engage and win the tackle and ruck has been associated with team success. To win the tackle and ruck, players have to perform specific techniques. These techniques have not been studied at the highest level of rugby union. Therefore the purpose of this study was to identify technical determinants of tackle and ruck performance at the highest level of rugby union. A total of 4479 tackle and 2914 ruck events were coded for the Six Nations and Championship competitions. Relative risk ratio (RR), the ratio of the probability of an outcome occurring when a characteristic was observed (versus the non-observed characteristic) was determined using multinomial logistic regression. Executing front-on tackles reduced the likelihood of offloads and tackle breaks in both competitions (Six Nations RR 3.0 Behind tackle, 95\%CI 1.9-4.6, ES = large, $\mathrm{p}<0.001$ ); Championship RR 2.9 Jersey tackle, 95\%CI 1.3-6.4, ES = moderate, $\mathrm{p}=0.01)$. Fending during contact increased the chances of offloading and breaking the tackle in both competitions (Six Nations RR 4.5 Strong, 95\%CI 2.2-9.2, ES = large, p= p<0.001; Championship RR 5.1 Moderate, 95\%CI 3.5-7.4, ES = large, $\mathrm{p}<0.001$ ). For the ruck, actively placing the ball increased the probability of maintaining possession (Six Nations RR 2.2, 95\%CI 1.1-4.3, ES = moderate, $\mathrm{p}=0.03$ ); Championship RR 4.0, 95\%CI 1.3-11.8, ES = large, $\mathrm{p}=0.01)$. The techniques identified in this study should be incorporated and emphasized during training to prepare players for competition. Furthermore, these techniques need to be added to coaching manuals for the tackle and ruck.

Keywords: Rugby Union; Tackle; Ruck; Performance 


\section{Introduction}

Rugby union is now amongst the most played and watched sports in the world, with an estimated 6.6 million players across 119 countries (Arnold and Grice, 2016). The sport is characterised by contact events where opposing players physically engage each other to compete for possession of the ball and prevent opponents from scoring points. The most frequently occurring contact events are the tackle and ruck, which occur with a mean of 116 times in an 80-minute match (Hendricks, Matthews, Roode, \& Lambert, 2014). Because of this high frequency of occurrence, the ability to repeatedly engage and win the tackle and ruck has been associated with overall team success (Jones, Mellalieu, \& James, 2004; Ortega, Villarejo, \& Palao, 2009; Wheeler, Askew, \& Sayers, 2010). For example, Ortega et al. (2009) reported that winning teams completed more tackles and regained ball possession at rucks more frequently than losing teams in the Six Nations competition. The nature of the tackle and ruck also exposes players to high risk of injury, with $72 \%$ of all match injuries attributable to these contact events (Williams, Trewartha, Kemp, \& Stokes, 2013). For these reasons, rugby union matches have been analysed to identify factors that should guide training of the tackle and the ruck, with the ultimate goal of improving performance and reducing the risk of injury to players (Burger, Lambert, Viljoen, Brown, Readhead, den Hollander, et al., 2016; Hendricks et al., 2014; Wheeler \& Sayers, 2009).

Based on match analyses studies, it is apparent that players have to execute specific actions and techniques to win the tackle and the ruck (Hendricks et al., 2014; Kraak \& 
Welman, 2014; Wheeler et al., 2010). For example, key tackler techniques associated with positive tackle performance are: (i) tacklers counter-acting the ball-carrier fend, (ii) tacklers executing shoulder tackles targeted at the mid-torso of the ball-carrier and (iii) tacklers leg-driving after contact (Hendricks et al., 2014). Although these studies refined the methods used to analyse the tackle and ruck performance during matches, and identified technical characteristics that should be coached during training to effectively prepare players for competition, work to date has noteworthy limitations. These limitations include: the use of a sample of matches in one competition (typically Super Rugby); account not being made of match situation (time period, match status, field position); or events and actions that are not described in enough technical detail to guide training or improve match strategies.

With the exception of the Rugby World Cup (played quadrennially), winning the Six Nations or the Championship competition is the ultimate measure of team success in International rugby union. However, research on these International competitions has been limited to the reporting of tackle and ruck frequency statistics (Jones et al., 2004; Kraak \& Welman, 2014; van Rooyen, 2012). World Rugby has recently highlighted a need to improve the technical abilities of all professional rugby union players (Quarrie et al., 2016), yet there is insufficient data to inform coaches of the technical demands and requirements to perform the tackle and ruck at the highest level of rugby union. Knowledge of the most effective tackle and ruck contact techniques in the Six Nations and the Championship could improve current coaching strategies and training design. 
hence, the purpose of this study was to identify technical determinants of tackle and ruck performance at the highest level of rugby union.

\section{Methods}

\section{Approach to the problem}

This study followed a similar approach to Hendricks et al. (2014), Hendricks et al. (2013) and Sewry et al. (2015) by using retrospective video analyses to determine the relationship between technical actions and performance outcomes in rugby union. In brief, video footage were analysed using Sports Code elite version 6.5.1, using an Apple iMac (Apple, USA). The analysis software allowed control over the speed at which each movement can be viewed, and the recording and saving of each coded instance into a database. During the analyses, the analyst could pause, rewind and watch the footage in slow motion. The highest frame frequency the analyst could slow down the motion of the footage was to $25 \mathrm{~Hz}$. Instances were coded using determinants and definitions described earlier (Hendricks et al., 2014; Hendricks, Karpul, Nicolls, \& Lambert, 2012; Hendricks \& Lambert, 2010), and those developed specifically for this study (Table 1). A tackle event was defined as any event where one or more tacklers (player or players making the tackle) attempted to stop or impede the ball-carrier (player carrying the ball) whether or not the ball- carrier was brought to ground (Fuller et al., 2008; Hendricks \& Lambert, 2010). Each tackle was coded for tackle-contact determinants (first instance of contact), post-tackle determinants, match-situation determinants and tackle outcomes (tackle break, offload, possession lost, ruck formed). If the outcome of the tackle was a ruck, the 
determinants of the ruck and the outcome of the ruck were subsequently coded. All video footage was obtained from the South African Rugby Union Video Database. To avoid bias towards a specific team or period during the competitions, each match was randomly selected using an on online random number generator (www.random.org). The study was approved by the University of Cape Town Human Research Ethics Committee (HREC Ref: 517/2015).

[Insert Table 1 here]

\section{Matches}

All matches from the 2014 Six Nations $(n=12)$ and 2014 Championship $(n=15)$ competitions were completely analysed for this study. This equated to a total of 4479 coded tackle contact events (Championship=1853 tackles; Six Nations=2626 tackles) and 2914 ruck events (Championship=1234 tackles; Six Nations=1680 tackles).

\section{Identification and selection of variables}

The variables needed to be valid (represent relevant and important aspects of tackle and ruck technique and performance), and the definitions thereof had to be clear and unambiguous. The validity of variables was assessed using methods described by (O'Donoghue, 2009). In brief, variables and operational definitions were based on published peer-reviewed studies in the area, and through consultation with coaches, sport 
scientists and rugby union administrators. To ensure the logical and content validity for describing attacker and defender actions, the list was more inclusive than exclusive. After the list of variables was established, a panel of coaches, sport scientists and rugby union administrators was consulted to review the validity and relevance of the variables, and the lucidity of the operational definitions. The panel agreed that the list and definitions for tackle and ruck descriptors were appropriate and clear, and no further changes were required.

\section{Coding of variables}

Each tackle was coded for tackle-contact determinants, post-tackle determinants, match situation determinants and tackle outcomes. If the outcome of the tackle was a ruck, the determinants of the ruck and the outcome of the ruck were subsequently coded. Tackle contact determinants were for when the ball-carrier contacted the tackler. The variable categories coded at this point were the type of tackle, the direction of the tackle, body region of the ball-carrier struck and the presence of a ball-carrier fend. Post-tackle determinants were for after the initial contact was made and consisted of variable categories such as leg drive by tackler, leg drive by ball-carrier and territorial change. After coding for tackle-contact determinants and post-tackle determinants, the outcome of the tackle was recorded. The ball-carrier either offloaded the ball, broke the tackle, lost possession of the ball or a ruck was formed. If a ruck was formed, ruck determinants and the outcome of the ruck were coded - number of attacking and defending players at the ruck, ball-carrier falling direction, whether ball-carrier actively presented the ball, the 
activity of the supporting players at the ruck and whether possession was maintained by the attacking team. Match determinant variables were coded both for the tackle and ruck, and consisted of match location (home vs. away), match time (in quarters), match status (score at the time of the contact event) and field position (vertical and horizontal quadrants).

One analyst coded all the variables. The analyst studied the variables and their corresponding definitions to make certain that each variable was understood. When the analyst observed behaviours that fulfilled the definitions (e.g. "Jersey tackle" - tackler holds ball-carrier's jersey before impeding ball-carrier with upper limbs) the event was coded. Despite using only one coder and all efforts to increase the objectivity of the methods, subjectivity is likely when human observation analyses performance (O'Donoghue, 2009).

\section{Reliability}

For intra-coder reliability, two matches were each coded twice using the variables and definitions described above. Coding of the same game was separated by at least one week (Wheeler et al., 2010). A second analyst followed the same procedure for the same two games for inter-reliability. Kappa statistics ( $\kappa \pm$ standard error $)$ evaluated intra- and intercoder reliability for each randomly selected match (James, Taylor, \& Stanley, 2007; Viera \& Garrett, 2005). Kappa values between 0.81 and 0.99 represent excellent agreement between repeated measures, and values between 0.61 and 0.80 represent 
“substantial agreement" (James et al., 2007; O'Donoghue, 2009; Viera \& Garrett, 2005).

Intra-coder reliability - overall for match 1 - was: contact variables $\kappa=0.98 \pm 0.16$, postcontact variables $\kappa=0.95 \pm 0.18$, ruck variables $\kappa=0.85 \pm 0.15$, and match situation variables $\kappa=0.97 \pm 0.22$. Overall for match 2 : contact variables $\kappa=0.98 \pm 0.16$, postcontact variables $\kappa=0.96 \pm 0.19$, ruck variables $\kappa=0.94 \pm 0.14$, and match situation variables $\kappa=0.97 \pm 0.22$. Total intra-coder reliability for the two matches were: contact variables $\kappa=0.98 \pm 0.16$, post-contact variables $\kappa=0.96 \pm 0.19$, ruck 19 variables $\kappa=90$ \pm 0.15 , and match situation variables $\kappa=0.97 \pm 0.22$.

Inter-coder reliability - overall, for match 1 was: contact variables $\kappa=0.81 \pm 0.15$, postcontact variables $\kappa=0.87 \pm 0.18$, ruck variables $\kappa=0.77 \pm 0.14$, and match situation variables $\kappa=0.98 \pm 0.13$. Overall for match 2 : contact variables $\kappa=0.85 \pm 0.15$, postcontact variables $\kappa=0.93 \pm 0.18$, ruck variables $\kappa=0.88 \pm 0.14$, and match situation variables $\kappa=0.96 \pm 0.13$. Total inter-coder reliability for the two games were as follows; contact variables $\kappa=0.84 \pm 0.10$, post-contact variables $\kappa=0.92 \pm 0.12$, ruck variables $\kappa$ $=0.87 \pm 0.10$, and match situation variables $\kappa=0.97 \pm 0.09$.

\section{Statistical Analyses}

Cohen's effect size ( $d$ ) and the Student's $t$-test compared the number of tackle and ruck events per match between the two competitions. Effect sizes of $<0.19,0.2-0.59,0.6-1.19$, and 1.2> were considered trivial, small, moderate, and large, respectively (Hopkins, Marshall, Batterham, \& Hanin, 2009). A two-tailed $p$-value was used for all tests, with 
the $a$ priori alpha level of significance set at $p<0.05$. Data are reported as mean \pm standard deviation.

Multinomial logistic regression identified technical contact determinants and match situations that were associated with tackle (offload, tackle break, ruck formed) and ruck (possession maintained) performance outcomes. All determinants were computed in one model, including the match-situation determinants. Separate models were conducted for each competition (Six Nations and Championship) and each contact event (tackle and ruck) - i.e. four multinomial logistic regression models with all relevant determinants were computed. Relative risk ratios (RR) and 95\% confidence intervals (95\% CIs) are reported. The RR is a ratio of the probability of the event (outcome) occurring in the observed determinant versus the non-observed determinant. To perform this analysis, determinant variables are computed relative to a referent or base variable. For example, for type of tackle, the base variable was shoulder tackle. For interpreting the multinomial logistic regression, if the $\mathrm{RR}$ of the variable is more than 1, the comparison determinant is more likely to occur, and if the RR of the variable is less than 1, the base variable is more likely to occur. The magnitude of this likelihood is represented by the RR value. RR values between 1.0-1.19, 1.2-1.89, 1.9-2.9, 3.0-5.69, 5.7-19 were considered, trivial, small, moderate, large and very large, respectively (www.sportsci.org). The alpha was set at $p<0.05$. Similar analyses of rugby union performance can be found in (Hendricks et al., 2014; Hendricks et al., 2013; Sewry et al., 2015). The suitability and equations for logistic regression can be found in (Hamilton, 2012; Huck, 2012). All statistics were computed using STATA 12 (StataCorp, USA). 


\section{Results}

\section{Number of contact events}

Players in the Six Nations competition performed $175 \pm 21$ tackle per a match. This was greater than the number of tackles in the Championship (154 \pm 36 tackles, $d=0.7$,

moderate, $p=0.07)$. The number of ruck events recorded per a match was $112 \pm 27$ for the Six Nations, and $103 \pm 30$ for the Championship ( $d=0.3$, small, $p=0.41)$.

[Insert Figure 1 here]

\section{Technical determinants related to tackle outcome}

Being tackled from the front reduced the likelihood of offloads and tackle breaks in both competitions (Table 2). Fending during contact increased the chances of offloading and breaking the tackle in both competitions. Moderate ball-carrier leg drive decreased the probability of offloading in the tackle in the Championship, whereas strong ball-carrier leg drive in the Six Nations increased the probability of offloading in the tackle. To break the tackle, ball-carrier leg drive increased the probability of a positive outcome in both competitions.

[Insert Table 2 here] 


\section{Technical determinants related to ruck outcome}

For the ruck, actively placing the ball increased the likelihood of maintaining possession (Six Nations RR 2.2, 95\%CI 1.1-4.3, effect size (ES) = moderate, $p=0.03$; Championship RR 4.0, 95\%CI 1.3-11.8, ES = large, $p=0.01$ ). In the Six Nations, ball-carriers falling sideward after the tackle had a higher probability of maintaining ball possession during the ruck contest (RR 3.2, 95\% CI 1.5-6.8, $\mathrm{ES}=$ large, $p=0.003$ ). In the Championship, having 3 to 5 defending players actively engaging in the ruck decreased the likelihood of the attacking team maintaining possession of the ball by $85 \%$ (RR $0.15,95 \%$ CI $0.0-0.5$, $\mathrm{ES}=$ small, $p=0.003)$. 


\section{Discussion}

This is the first study to identify technical determinants and their association both with tackle and ruck performance in professional International competition. In both competitions, ball-carriers are more likely to offload or break the tackle if they execute a fend and drive the legs after contact, whereas tacklers can prevent an offload or tackle break by executing a front-on shoulder tackle with leg drive. The ball-carrier and tackler technical determinants associated with tackle contact success in this study are comparable to contact techniques associated with success in Super Rugby (Hendricks et al., 2014; Sewry et al., 2015; Wheeler et al., 2010). Furthermore, these ball-carrier and tackler technical determinants reduce the risk of injury in the tackle (Burger, Lambert, Viljoen, Brown, Readhead, den Hollander, et al., 2016). The commonality both of ball-carrier and tackler contact techniques associated with success in International competitions, and considering previous reports in Super Rugby, provide strong empirical evidence for the importance of these contact techniques for performance. While coaches and coaching manuals might recommend some of these techniques, for example, front-on shoulder tackles (Hendricks, den Hollander, Tam, Brown, \& Lambert, 2015; Hendricks, Jordaan, \& Lambert, 2012; Hendricks \& Sarembock, 2013), other contact techniques such fending are not part of standard contact training (Hendricks \& Lambert, 2010; Hendricks et al., 2014).

While previous research on the ruck has attempted to show the importance of winning the ruck for overall team success (Kraak \& Welman, 2014) and the relationship between ruck 
strategies and ruck outcomes (Wheeler, Mills, Lyons, \& Harrinton, 2013), this is the first study to report on the technical requirements to win the ruck contest. From an attacking perspective, ball-carrier actions immediately after the tackle were the most notable determinants of ruck success. Justifiably, ball-carriers falling sideward and then actively placing the ball makes it harder for the immediate defenders to compete for the ball on the ground. For defense, three to five defending players actively engaged in the ruck increased the likelihood of regaining possession of the ball. This finding supports Kraak and Welman (2014), which showed the defending team is more likely to win the ruck when more defenders than attackers are present. If a tackle does not result in losing the ball, an offload, or tackle break, a ruck is formed $-65 \%$ of all tackles in this study resulted in a ruck. For coaching, coaches should include tackle and ruck techniques in the same drill. For example, after demonstrating the techniques to carry the ball into contact, the ball-carrier should also be expected to fall sideward and place the ball.

Although the magnitude of effects were small to moderate, field position, match location, match status and match quarter were associated with tackle and ruck performance. These factors influence the design of task constraints for technical training drills and plans for match strategy (Burger, Lambert, Viljoen, Brown, Readhead, \& Hendricks, 2016; Headrick et al., 2012; Hendricks et al., 2013).

Recently, contact phases of rugby union, specifically the tackle, have come under scrutiny, alongside a recommendation by a World Rugby expert group to improve the technical abilities of all professional rugby union players (Quarrie et al., 2016; Tucker, 
Raftery, \& Verhagen, 2016). Subsequently, a call for the development of a contact-skill programme was made (Hendricks, Till, Brown, \& Jones, 2016). The results of this study provide evidence to assist the design of such a programme and highlight techniques that should be emphasized during training. Also, the contact techniques in this study associated with success in this study are recommended for other standards of play.

Even though the objective of this study was achieved, effective execution of contact techniques also relies on player's physical conditioning and tactical awareness (Hendricks \& Lambert, 2014; Hendricks et al., 2013; Sewry et al., 2015). Physical fatigue reduces player's technical contact ability (Burger, Lambert, Viljoen, Brown, Readhead, \& Hendricks, 2016; Gabbett, 2008). Similarly, mental fatigue reduces technical ability in football players, and probably affect contact technique in rugby union (Smith et al., 2016). Tactically, the quality and speed of the defense have been positively associated with winning contact situations (Hendricks et al., 2013; Sewry et al., 2015). Although more work is required to improve understanding of relationships among technique, fatigue, tactics and performance, coaches should consider these factors when designing and developing contact-technique training.

\section{Conclusion}

This is the first study to identify technical determinants of tackle and ruck performance in the Championship and Six Nations competitions. Fending and leg driving during contact increased the likelihood of a ball-carrier offload or tackle break, while front-on shoulder 
tackles with leg drive decreased the likelihood of a ball-carrier offload or tackle break. To win ruck contests, ball-carriers should fall sideward and actively place the ball, whereas the defending team need to commit three to five players to increase their chances of winning the ruck. These techniques should be incorporated and emphasized during training to prepare players for competition. Furthermore, these techniques need to be added to coaching manuals for the tackle and ruck.

\section{Acknowledgements}

The authors would like to thank the technical department of the South African Rugby Union for providing the recorded matches for the study. 


\section{References}

Arnold, P., and Grice, M. (2016). The economic impact of World Rugby 2015. Ernst and Young Report, 5-6.

Burger, N., Lambert, M. I., Viljoen, W., Brown, J. C., Readhead, C., den Hollander, S., \& Hendricks, S. (2016). Mechanisms and factors associated with tackle-related injuries in South African youth rugby union players. The American Journal of Sports Medicine, 45, 278-285.

Burger, N., Lambert, M. I., Viljoen, W., Brown, J. C., Readhead, C., \& Hendricks, S. (2016). Tackle technique and tackle-related injuries in high-level South African rugby union under-18 players: real-match video analysis. British Journal of Sports Medicine, $50,932-938$.

Fuller, C. W., Ashton, T., Brooks, J. H., Cancea, R. J., Hall, J., \& Kemp, S. P. (2008). Injury risks associated with tackling in rugby union. British Journal of Sports Medicine, 44, 159-167.

Gabbett, T. J. (2008). Influence of fatigue on tackling technique in rugby league players. The Journal of Strength \& Conditioning Research, 22, 625-632.

Hamilton, L. C. (2012). Statistics with Stata: version 12. Boston: Brooks/Cole, Cengage Learning.

Headrick, J., Davids, K., Renshaw, I., Araújo, D., Passos, P., \& Fernandes, O. (2012). Proximity-to-goal as a constraint on patterns of behaviour in attacker-defender dyads in team games. Journal of Sports Sciences, 30, 247-253.

Hendricks, S., den Hollander, S., Tam, N., Brown, J., \& Lambert, M. (2015). The relationships between rugby players' tackle training attitudes and behaviour and their 
match tackle attitudes and behaviour. BMJ Open Sport \& Exercise Medicine. Online. doi: 10.1136/bmjsem-2015-000046

Hendricks, S., Jordaan, E., \& Lambert, M. (2012). Attitude and behaviour of junior rugby union players towards tackling during training and match play. Safety Science, 50, 266-284.

Hendricks, S., Karpul, D., Nicolls, F., \& Lambert, M. (2012). Velocity and acceleration before contact in the tackle during rugby union matches. Journal of Sports Sciences, 30, 1215-1224.

Hendricks, S., \& Lambert, M. (2010). Tackling in rugby: coaching strategies for effective technique and injury prevention. International Journal of Sports Science and Coaching, $5(1), 117-136$.

Hendricks, S., \& Lambert, M. I. (2014). Theoretical model describing the relationship between the number of tackles in which a player engages, tackle injury risk and tackle performance. Journal of Sports Science \& Medicine, 13, 715-717.

Hendricks, S., Matthews, B., Roode, B., \& Lambert, M. (2014). Tackler characteristics associated with tackle performance in rugby union. European Journal Sport Science, 14, 753-762.

Hendricks, S., Roode, B., Matthews, B., \& Lambert, M. (2013). Defensive strategies in rugby union. Perceptual \& Motor Skills, 117, 65-87.

Hendricks, S., \& Sarembock, M. (2013). Attitudes and behaviours of top-level junior rugby union coaches towards the coaching of proper contact technique in the tackle - a pilot study. South African Journal of Sports Medicine, 25, 8-11. 
Hendricks, S., Till, K., Brown, J. C., \& Jones, B. (2016). Rugby union needs a contact skill-training programme. British Journal of Sports Medicine. Online.

doi: 10.1136/bjsports-2016-096347

Hopkins, W., Marshall, S., Batterham, A., \& Hanin, J. (2009). Progressive statistics for studies in sports medicine and exercise science. Medicine \& Science in Sports \& Exercise, 41, 3-13.

Huck, S. (2012). Bivariate, multiple and logistic regression: reading statistics \& research 6. Boston: Peason Education Inc.

James, N., Taylor, J., \& Stanley, S. (2007). Reliability procedures for categorical data in performance analysis. International Journal of Performance Analysis in Sport, 7, 1-11. Jones, N. M., Mellalieu, S. D., \& James, N. (2004). Team performance indicators as a function of winning and losing in rugby union. International Journal of Performance Analysis in Sport, 4, 61-71.

Kraak, W. J., \& Welman, K. E. (2014). Ruck-play as performance indicator during the 2010 Six nations championship. International Journal of Sports Science \& Coaching, 9, $525-537$.

O'Donoghue, P. (2009). Research methods for sports performance analysis. New York : Routledge.

Ortega, E., Villarejo, D., \& Palao, J. M. (2009). Differences in game statistics between winning and losing rugby teams in the Six Nations tournament. Journal of Sports Science and Medicine, 8, 523-527.

Quarrie, K. L., \& Hopkins, W. G. (2008). Tackle injuries in professional rugby union. The American Journal of Sports Medicine, 36, 1705-1716. 
Quarrie, K. L., Raftery, M., Blackie, J., Cook, C. J., Fuller, C. W., Gabbett, T. J., . .

Kemp, S. (2016). Managing player load in professional rugby union: a review of current knowledge and practices. British Journal of Sports Medicine. Online.

doi:10.1136/bjsports-2016-096191

Sewry, N., Lambert, M., Roode, B., Matthews, B., \& Hendricks, S. (2015). The

relationship between playing situation, defence and tackle technique in rugby union.

International Journal of Sports Science \& Coaching, 10, 1115-1128.

Smith, M. R., Coutts, A. J., Merlini, M., Deprez, D., Lenoir, M., \& Marcora, S. M.

(2016). Mental fatigue impairs soccer-specific physical and technical performance.

Medicine \& Science in Sports \& Exercise, 48(2), 267-276.

Tucker, R., Raftery, M., \& Verhagen, E. (2016). Injury risk and a tackle ban in youth

rugby union: reviewing the evidence and searching for targeted, effective interventions-a critical review. British Journal of Sports Medicine, 50, 921-925.

van Rooyen, M. K. (2012). A statistical analysis of tackling performance during international rugby union matches from 2011. International Journal of Performance Analysis in Sport, 12, 517-530.

Viera, A. J., \& Garrett, J. M. (2005). Understanding interobserver agreement: the kappa statistic. Family Medicine, 37, 360-363.

Wheeler, K., \& Sayers, M. (2009). Contact skills predicting tackle-breaks in rugby union. International Journal of Sports Science \& Coaching, 4, 535-544.

Wheeler, K. W., Askew, C. D., \& Sayers, M. G. (2010). Effective attacking strategies in rugby union. European Journal of Sport Science, 10, 237-242. 
Wheeler, K. W., Mills, D., Lyons, K., \& Harrinton, W. (2013). Effective defensive strategies at the ruck contest in rugby union. International Journal of Sports Science \& Coaching, 8, 481-492.

Williams, S., Trewartha, G., Kemp, S., \& Stokes, K. (2013). A meta-analysis of injuries in senior men's professional rugby union. Sports Medicine, 43, 1043-1055. 